\title{
Mediation with pseudomediation controlled: Chaining is not an artifact!'
}

\author{
Rudolph W. Sehulz, George E. Weaver and Stanley Ginsberg \\ UNIVERSITY OF IOWA
}

\begin{abstract}
Abstraet
Mandler \& Earhard (1964) have shed doubt on the legitimacy of interpreting facilitated Stage 3 performance in the paired associate $\mathrm{A}-\mathrm{B}, \mathrm{B}-\mathrm{C}, \mathrm{A}-\mathrm{C}$ chaining paradigm as being due to mediating associations. This problem was examined further in the present study by investigating simultaneously four three-stage PA paradigms, Mandler and Earhard's two paradigms, plus an additional control and the "classic" chaining paradigm. Performance in Stage 3 under chaining conditions was clearly and significantly superior to performance under all other conditions. No evidence for so-called "pseudomediation" effects was obtained. It was concluded that a mediational interpretation for the observed facilitation under chaining conditions remains highly tenable.
\end{abstract}

\section{Introduetion}

In a three-stage PA transfer situation, Mandler \& Earhard (1964) have recently provided evidence to support their challenging contention that it may not be parsimonious to infer that mediating associations account for the typical finding that $\mathrm{A}-\mathrm{C}$ learning proceeds more rapidly in the $\mathrm{A}-\mathrm{B}, \mathrm{B}-\mathrm{C}, \mathrm{A}-\mathrm{C}$ chaining than in the $A-B, D-C, A-C$ control paradigm. They suggest, instead, that this result be attributed to decreased interference from A-B associations during A-C learning under chaining conditions as the result of the weakening of these assoications via the unlearning in Stage 2 of the B-A associations. To test this hypothesis they compared the Stage 2 and 3 performance in an $A-B, B-C, A-E$ paradigm with that of an A-B, D-C, A-E paradigm. They found, as predicted, that in Stage 2 the learning of D-C was more rapid than the learning of $\mathrm{B}-\mathrm{C}$ and that in Stage $3 \mathrm{~A}-\mathrm{E}$ was learned more rapidly in the A-B, B-C, $\mathrm{A}-\mathrm{E}$ than in the A-B, D-C, A-E paradigm.

Though Mandler and Earhard's results are clearly in accord with their hypothesis, it seems evident immediately that their design was incomplete. Namely, it does not rule out the possibility that only part of of the total difference in performance under chaining vs. control conditions is directly attributable to the mechanisms they have postulated, and that the remainder of the difference can still be legitimately attributed to facilitation via "bonafide"' mediating associations. The present study was designed, therefore, to evaluate further the latter possibility while, at the same time, attempting to replicate Mandler and Earhard's results with somewhat different materials and procedures.

\section{Method}

No effort was made to replicate in detail the procedures and materials employed by Mandler \& Earhard
(1964). Instead, the present study employed the procedures which have been devised to implement our own program of research concerned with mediating processes.

The following four three-stage PA paradigms were employed: (1) A-B, B-E, A-E (2) A-B, B-C, A-E (3) $A-B, D-C, A-E$ (4) A-B, D-E, A-E. Hereafter, these paradigms will be referred to in terms of Stage 2 since it represents the only source of differential treatment among them. The B-E condition conforms to the familiar chaining paradigm with Condition D-E as the most appropritate control for it. Conditions B-C and D-C represent, respectively, Mandler and Earhard's experimental and control conditions. A total of $80 \mathrm{Uni}-$ versity of Iowa undergraduates, naive with respect to verbal learning experiments, served as Ss. The Ss were assigned to paradigms randomly, $20 \mathrm{Ss}$ per paradigm.

The A terms in the 10-pair PA lists defining the above conditions consisted of low $m$ Taylor (1959) paralogs. Low $m$ Archer (1960) CVC trigrams served as $\mathrm{C}$ and $\mathrm{E}$ terms. Common nouns ( $\mathrm{T}-\mathrm{L}$ frequencies of AA), having minimal associative-overlap in the Russell \& Jenkins (1954) norms, were used as B and D terms. Intralist and interlist formal similarity was as low as possible in all paradigms.

List A-B (Stage 1 for all paradigms) was learned by the study-test method. Each pair was presented for 2 sec. on study trials. On test trials, only the stimulus term was presented for $2 \mathrm{sec}$. and $\mathrm{S}$ was required to recall the response term. The lists in Stages 2 and 3 were also learned by the study-test method; however, the test trials took the form of a four-alternative multiple-choice test for each pair in these stages with the correct response plus three other response terms from a given list as alternatives. The positions of the correct and incorrect alternatives were appropriately and systematically balanced over trials. The testtrial alternatives had the numbers 1 to 4 below them. The Ss responded with the number of the alternative they had chosen. The study interval was $2 \mathrm{sec}$. and the test interval $3 \mathrm{sec}$. per item. Learning in Stages 1 and 2 was to a criterion of two successive perfect trials. Stage 3 consisted of 10 study and test trials. The orders of item presentation were randomized throughout the three stages to prevent serial learning. All lists were presented on a Stowe memory drum.

\section{Results and Discussion}

The number of trials required to attain criterion on List A-B was virtually identical for the four conditions with means ranging from 10.05 to 11.20 ( $<<1$ ); hence, 
the Ss serving under the various conditions may be regarded as comparable in ability. ${ }^{2}$ Performance in Stage 2 agreed with Mandler and Earhard's findings in that the mean of 9.38 for trials to attain criterion under Conditions $\mathrm{B}-\mathrm{E}$ and $\mathrm{B}-\mathrm{C}$ was reliably greater than the mean of 6.12 for Conditions $D-C$ and $D-E, t(78)=2.68$; $\mathrm{p}<.01$. Performance as a function of paradigms and trials in Stage 3, the "critical" stage, is shown in Fig. 1. From Fig. 1, it is clearly apparent that performance in Condition B-E (chaining) was markedly superior to performance under the remaining three conditions whose performance was essentially identical. In terms of mean total number of correct responses over the 10 Stage 3 trials, the smallest difference between Condition $\mathrm{B}-\mathrm{E}$ and the other three conditions yielded a $t(38)$ of 5,$75 ; p<.01$ while the largest difference among Conditions B-C, D-C, and D-E was associated with a $t(38)$ of only $0.11 ; p>.20$. Quite evidently, at least under the present conditions, the results for Stage 3 performance fail to confirm those obtained by Mandler and Earhard and, are instead, strongly favorable to a mediational interpretation of performance under Condition B-E.

It should, however, be noted that the present B-E condition was undoubtly rather uniquely favorable for the utilization (cf., Schulz \& Lovelace, 1964; Horton, 1964) of mediating associations (i. e., highly available mediators, a long test-list anticipation interval and minimal attenuation of effective utilization of mediating associations due to low availability of test-list response terms). Put another way, the present results should not, and cannot, be interpreted as casting doubt directly on the reproduceability of Mandler and Earhard's results. The differences in the material and procedural details of our study and theirs preclude such an interpretation. More appropriately, it is the generality of their results that is questionable.

Nevertheless, it seems clear from the present results that, given appropriate conditions, the inference that mediating associations facilitate performance of the $A-B, B-E, A-E$ chaining paradigm relative to an A-B, $\mathrm{D}-\mathrm{E}, \mathrm{A}-\mathrm{E}$ control paradigm is not based on an "artifact." Indeed, the large and prolonged difference in Stage 3 performance favoring Condition B-E over the other conditions suggests that the present technique may be exceptionally suitable for the assessment of the effects of a wide range of variables on the mediation process.

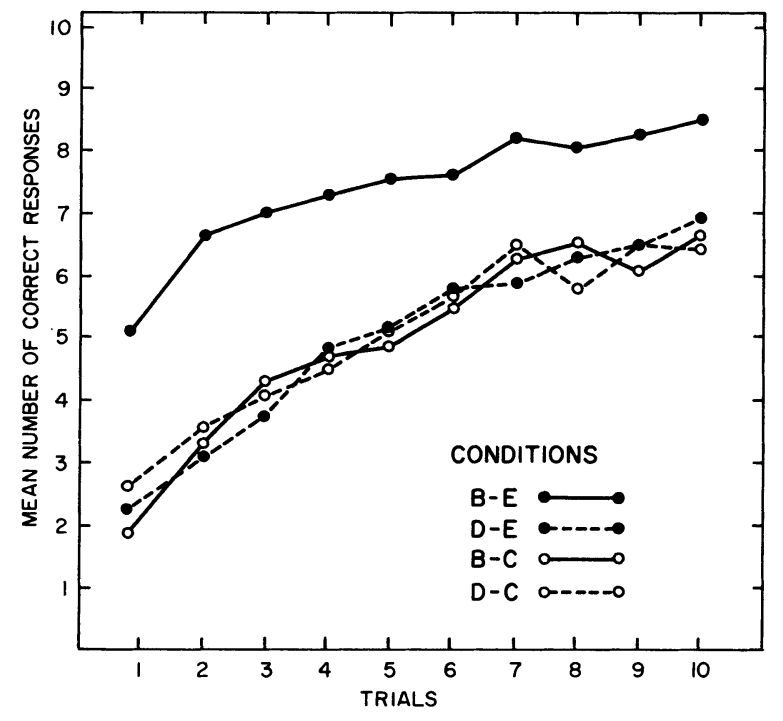

Fig. 1. Stage $3 \mathrm{PA}$ performance in terms of mean number of correct responses as a function of transfer paradigms and trials.

\section{Referenees}

ARCHER, E. J. A re-evaluation of the meaningfulness of all possible CVC trigrams. Psychol. Monogr., 1960,74, No.10 (Whole No. 497). HORTON, D. L. The effects of meaningfulness, awareness, and type of design in verbal mediation. J.verbal Learn. verbal Behav., 1964, 3, 187-194.

MANDLER, G., \& EARHARD, B. Pseudomediation: Is chaining an artifact? Psychon. Sci., 1964, 1, 247-248.

RUSSELL, W. A., \& JENKINS, J. J. The complete Minnesota norms for responses to 100 words from the Kent-Rosanoff word association test. Tech. Rep. No. 11, ONR Contract N8 onr - 66216, Univer. of Minnesota, 1954.

SCHULZ, R. W., \& LOVELACE, E. A. Mediation in verbal pairedassociate learning: The role of temporal factors. Psychon. Sci., 1964, 1, 95-96.

TAYLOR, J. D. The meaningfulness of 320 words and paralogs. Unpublished doctoral dissertation, Duke Univer., 1959.

\section{Notes}

1. This research was supported by Grant GB2835 from the National Science Foundation.

2. Because of time limitations ( $75 \mathrm{~min}$.) and the stringent criterion for Stage 1 learning, only Ss who met the criterion within 20 trials were retained. No bias is introduced because all Ss learned the same list in Stage 1. 